IZA DP No. 6674

Myth or Fact?

The Beauty Premium across the Wage Distribution

Karina Doorley

Eva Sierminska

June 2012 


\title{
Myth or Fact? The Beauty Premium across the Wage Distribution
}

\author{
Karina Doorley \\ CEPS/INSTEAD \\ and University College Dublin \\ Eva Sierminska \\ CEPS/INSTEAD, \\ DIW Berlin and IZA
}
Discussion Paper No. 6674
June 2012

\author{
IZA \\ P.O. Box 7240 \\ 53072 Bonn \\ Germany \\ Phone: +49-228-3894-0 \\ Fax: +49-228-3894-180 \\ E-mail: iza@iza.org
}

\begin{abstract}
Any opinions expressed here are those of the author(s) and not those of IZA. Research published in this series may include views on policy, but the institute itself takes no institutional policy positions.

The Institute for the Study of Labor (IZA) in Bonn is a local and virtual international research center and a place of communication between science, politics and business. IZA is an independent nonprofit organization supported by Deutsche Post Foundation. The center is associated with the University of Bonn and offers a stimulating research environment through its international network, workshops and conferences, data service, project support, research visits and doctoral program. IZA engages in (i) original and internationally competitive research in all fields of labor economics, (ii) development of policy concepts, and (iii) dissemination of research results and concepts to the interested public.
\end{abstract}

IZA Discussion Papers often represent preliminary work and are circulated to encourage discussion. Citation of such a paper should account for its provisional character. A revised version may be available directly from the author. 


\title{
ABSTRACT \\ Myth or Fact? \\ The Beauty Premium across the Wage Distribution*
}

\begin{abstract}
We apply an innovative technique to allow for differential effects of physical appearance and self-confidence across the wage distribution, as traditional methods can confound opposing effects at either end of the wage distribution. Comparing the effects of beauty and confidence measures in two countries (Germany and Luxembourg), we find that wages are more driven by looks than self-esteem. Counterfactual wage distributions, constructed using distribution regression, show a beauty premium for women at the bottom of the wage distribution. However, most of this is explained by the fact that attractive women have better labor market attributes than their unattractive counterparts. We find a large wage premium for attractive men throughout the wage distribution which is largely unexplained by labor market attributes. There is a small wage penalty for self-confident individuals, particularly men, although their labor market characteristics are generally better than their less confident counterparts. We show that the difference in characteristics between beautiful and plain people contributes to the beauty premium identified using traditional models, particularly for women. Isolating the characteristic effect from the unexplained effect of beauty on wages leads to smaller beauty premium for women.
\end{abstract}

JEL Classification: $\quad$ D31, J24, J30, J70

Keywords: $\quad$ wages, distribution, physical appearance, discrimination

Corresponding author:

Eva Sierminska

CEPS/INSTEAD

3 , avenue de la Fonte

4364 Esch-sur-Alzette

Luxembourg

E-mail: eva.sierminska@ceps.lu

\footnotetext{
* The authors would like to thank Kevin Denny, Dan Hamermesh, Ronald Oaxaca, Philippe Van Kerm and the participants of the $\mathrm{C} / \mathrm{l}$ seminar series for helpful suggestions and comments. This research is part of the MeDIM project Advances in the Measurement of Discrimination, Inequality and Mobility supported by the Luxembourg 'Fonds National de la Recherche' (contract FNR/06/15/08) and by core funding for CEPS/INSTEAD by the Ministry of Higher Education and Research of Luxembourg.
} 
'All that glitters is not gold' -W. Shakespeare

\section{Introduction}

Like in so many areas of life, Shakespeare had excellent insight into the sometimes misleading effects of physical appearance. In this paper, we examine whether the glitter of an appealing physical appearance leads to higher pay across the distribution. We examine two type of beauty measures; an interviewer-assessed objective measure of beauty and a self-reported measure, to see whether beauty or ego has an impact on wages. Hamermesh and Biddle (1994), in their seminal paper based on self-reported beauty, show the existence of an average wage penalty of $5-10 \%$ for being plain and an average wage premium of $5-10 \%$ for being beautiful in the US and Canada. Most other studies that find a positive effect of looks on earnings also identify average effects (Biddle and Hamermesh (1998), Harper (2000), Hamermesh et al. (2002), Mobius and Rosenblat (2006) and Sen et al. (2010)). While measuring average effects is quite informative and convenient, it also has substantial drawbacks, as opposing effects that exist across the distribution may be confounded in the summary effect, as has been discovered for other variables that affect wages, such as gender (Bonjour and Gerfin (2001)).

The effect of beauty on wages throughout the distribution has not been been decomposed into the part attributable to characteristics and the part due to beauty, or the unobservables that beauty proxies. The effect of beauty may vary across the distribution because different points of the distribution correspond to different job types, which pay a different premium for looks. Better looking people, ceteris paribus, may have more opportunities to advance and have higher wages, while less attractive people may need to compensate with their qualifications and other traits, and the extent of these differences may vary depending on job types and differences in productivity and, consequently, where the individual is located in the wage distribution. In this paper, our goal is to examine the effect of beauty on earnings across the wage distribution using an innovative technique and new data.

In studies that use self-assessed beauty as the main explanatory variable one problem is reverse causality, whereby higher-wage people feel better about themselves and, as a result, report that they are better-looking. ${ }^{1}$ To address this critique, we use a unique dataset that contains both measures: a self-reported and interviewer-reported objective measure that allows us to disentangle the different effects. To ensure that our analysis is not subject to further reverse causality, whereby higher wage people with similar other characteristics take more care of their appearance due to the extra disposable income, we use the self-reported measure of beauty as a proxy for confidence in physical appearance to control for this.

Our contribution to the literature is as follows. First, we demonstrate that the effect of beauty varies across the wage distribution. Second, we use both self-assessed and interviewer-assessed measures of attractiveness to infer how much of the effect is due to physical appearance and how much is due to a person's own assessment of their physical

\footnotetext{
${ }^{1}$ Past research indicates better-looking people may actually be more confident before they enter the labor market (e.g. Persico et al. (2004)) and have other labor market enhancing skills (e.g.Feingold (1992))
} 
appearance, or confidence. Third, we devise a classification of occupations based on the importance of beauty. Fourth, most of the research done on this topic has been for AngloSaxon countries. In this paper, we provide evidence for two new countries, Germany and Luxembourg. Finally, we show how distribution regression (DR) a method little used in this literature and initially used to model excess returns on financial markets, is a useful tool in decomposing wage differentials by physical appearance across the wage distribution. The advantage of the DR method is that, in a flexible and visually appealing way, we can identify the channel through which beauty (or confidence) affects wages across the distribution. Do more attractive people have inherently better labor market characteristics or is there a beauty premium whereby, all else equal, more attractive people earn more money, simply because they are attractive or think that they are attractive?

We find that a beauty premium exists at the bottom of the distribution for women and throughout the distribution for men. This is explained by the fact that attractive women have better labor market attributes than their unattractive counterparts. For men this outcome is largely unexplained by labor market attributes. The effect of confidence is ambiguous for women and confident men suffer a wage penalty across the distribution but their characteristics are generally better than for their less confident counterparts. Overall, we find that most of the wage differences between confident and unconfident individuals are due to characteristics. We show that the difference in characteristics between beautiful and plain people contributes to the beauty premium identified using traditional models, particularly for women. Isolating the characteristic effect from the unexplained effect of beauty on wages leads to smaller beauty premium for women.

In section 2 we provide some background information on prior modeling of the effect of physical appearance on various outcome variables and the previous literature. Section 3 describes the data and variable construction. In Section 4 we outline our methodology. Sections 5 and 6 discuss the results and Section 7 concludes.

\section{Background}

Biddle and Hamermesh (1998), Harper (2000), Hamermesh et al. (2002), Mobius and Rosenblat (2006) and Sen et al. (2010), using different methods, all find evidence of a positive relationship between physical appearance and earnings. ${ }^{2}$ This relationship has been shown to be different for men and women and to vary by country. There is a significant effect only for women in the United States (e.g. French (2002)) and only for men in Australia (e.g. Leigh and Borland (2012)) and within professions (Biddle and Hamermesh (1998), Sachsida et al. (2003)). A theoretical framework on this issue is offered by Jackson (1992). In her model, both the sociobiological (reproductive potential) and sociocultural (cultural values) perspectives predict that physical attractiveness has greater implications for females than males. Interestingly, despite the increased prevalence of anti-discrimination legislation, the return to beauty has beauty has been found to be stable in Australia over the last thirty years Leigh and Borland (2012).

There are a number of possible explanations for the relationship between physical appearance and earnings. These have been categorized into direct and indirect effects. Direct

\footnotetext{
${ }^{2}$ For a recent summary of the literature see Hamermesh (2011).
} 
effects, first elaborated by Hamermesh and Biddle (1994), include pure employer discrimination, customer discrimination and occupational crowding. The indirect effects are harder to pin down but a number of theories have been put forward. Mocan and Tekin (2010) find evidence that being an unattractive student in high school may hinder human capital development, due to preferential treatment of attractive students. This will have a knock-on effect on earnings later in life. Mobius and Rosenblat (2006) examine different channels through which beauty may affect wages and identify the stereotype channels and taste-based discrimination.

In a series of other papers, researchers have examined whether there is interviewer based discrimination in favor of better-looking people (e.g. Marlowe et al. (1996), Watkins and Johnston (2000), Lopez Boo et al. (2012)) and find that more attractive people receive more favorable treatment.

\section{Data and Descriptives}

We use data for Germany and Luxembourg in our analysis. The 2008 German Social Survey contains a unique set of variables on physical appearance: interview-assessed and self-reported physical appearance of the respondent. For Luxembourg, we rely on questions from the physical discrimination module of the 2007 wave of PSELL3/EUSILC. Here, our main variables of interest are the respondent's opinion of how important physical appearance is in the labor market, their self-assessed physical appearance and their hourly wages.

\subsection{Beauty Categories}

Given the issue of reverse causality between beauty and wages mentioned in the introduction, we will emphasize the distinction between self-reported and objective measures of beauty and our main results will relate to the effect of beauty (interviewer reported) on wages in Germany, after controlling for confidence (self reported).

We define attractiveness based on the interviewer-assessed objective measure of beauty and confidence based on the self-reported measure of beauty. We take advantage of several questions.

In the Luxembourg questionnaire, the question is about self-assessed beauty:

Considering now your general physical appearance (height, corpulence, color of the skin, face, etc.). On a scale of 1 to 10, 1 being 'very little attractive' and 10 being 'very attractive' how do you think people around you rate your physical appearance (in comparison to others of the same age and sex)?

We use this question to create 2 categories of confidence: above and under average. We examine the response behavior for this variable by age and gender and find the mean to be 6.5 and the median to be 7 . Consequently we define an individual to have above average confidence if the variable equals $7-10$, and below average confidence if it equals $1-6{ }^{3}$ We treat proxy respondents, i.e. those who answered this question for somebody

\footnotetext{
${ }^{3}$ Hamermesh (2012) finds that absolute rather than relative measures have a greater impact on labor
} 
else in the household, separately ${ }^{4}$ and classify these responses as objective measures of beauty, although we treat this as a crude objective measure as it could be confounded by the relationships that the proxy may have with the respondent. The mean of this variable is 7.3 while the median is 7 . Therefore, we define above average beauty as a response of 8-10 and below average as a response of 1-7.

In Germany, the interviewer is asked at the beginning and at the end of the interview: Please assess the attractiveness of the respondent. Please come to a spontaneous decision. This is on a scale of 1 to 11 , where 1 is 'unattractive and 11 'attractive'. We interpret this as an objective measure of beauty. The respondent is also asked to assess their own physical appearance on the same scale. We interpret this subjective measure as confidence. ${ }^{5}$ The mean and median response is 7 for confidence and 7.7 and 8 respectively, for objective beauty. Consequently, we define an individual as being attractive if the objective variable equals 8-11, and unattractive if it equals 1-7. The individual is classed as confident if the subjective variable equals 7-11 and unconfident otherwise.

Based on this classification, in table 1, we find that working women and men are equally likely to report above and below average beauty and confidence for both types of measures in Luxembourg and Germany. There is a slight statistically significant difference in Germany for the beauty measure, with women being more likely to report better looks.

\subsection{Occupation: Dressy and Non-dressy}

Hamermesh and Biddle (1994) hypothesize that people sort into occupations where physical appearance may affect productivity. To identify these occupations, we take advantage of a question in the special discrimination module in Luxembourg regarding the role of beauty in the work place: Do you think that the physical appearance (height, corpulence, color of the skin, face, etc.) plays an important role in the professional life and the career? The answer is on a 1-5 scale (very important, important, of little importance, not important, no opinion). We use this question to construct two types of occupation categories based on the role of looks: dressy or non-dressy.

The perceived importance of physical appearance in each of the occupations can be found in Figure A1. In the non-dressy category we include occupations where, either most people reported looks as unimportant or the job does not entail a lot of people interaction. This category includes farm workers, artists and crafts people, machine operators and blue-collar workers. In all of these occupations people are more likely to state that looks are "not important" than that they are "very important." The dressy occupation category includes occupations where human interaction is an important component of day to day activities. These include supervisors and managers, intellectual professions, intermediate professions, administrative employees and service and sales employees. We use the same occupational classification in Germany. The outcome of these classification can be found

\footnotetext{
market outcomes.

${ }^{4}$ In a previous version of the paper we did not find any significant effect on wages of having a proxy respondent (Doorley and Sierminska (2011)).

${ }^{5}$ The correlation between the self-reported and objective measure is 0.3260 , which implies that about $10 \%\left(0.326^{2}\right)$ of the variation in self-reported beauty is related to the variation in objective beauty, which is quite low.
} 
in Table 1 bottom panel, which shows that looks are indeed perceived as being more important in the dressy occupation category than in the non-dressy category. We also observe a statistically significant higher concentration of attractive and confident people in the dressy profession for both countries (results available from authors).

\subsection{Sample, Dependent variable and Covariates}

In our sample, we focus on 18 to 64 year olds. We exclude those who work more than one job, the self-employed and all those who work over 70 hours per week. In Luxembourg, we are left with a sample of 2939 women (1578 workers) and 2837 men (2180 workers). From this sample we have measures of objective beauty (confidence) for 428 (2511) women and 809 (2029) men. In Germany, we have 1220 women (795 workers) and 1, 198 men (910 workers) for whom we have information on objective beauty and confidence.

The explanatory variables used to model wages include education, work experience, ${ }^{6}$ nationality, marital status, health and job characteristics (dressy profession, temporary, part-time, civil servant, company size). For summary statistics relating to these variables, see Tables A1 and A2.

Comparing hourly wages across various beauty categories in Table 2 indicates that attractive men and women report higher wages in Germany. Confident women also report higher wages in Germany. In Luxembourg, there is no statistically significant variation in wages between individuals with low and high confidence although attractive men seem to have lower wages.

Looking at the dressy and non-dressy occupation categories separately in the same table, we find that, contrary to our expectation, there is no correlation between attractiveness or confidence and wages in the dressy profession. Attractive and confident people, in the non-dressy profession however, report higher wages in Germany.

To summarize, raw wages indicate that there exists a beauty premium for women and men in Germany, overall and in the non-dressy profession and a confidence premium for females overall, and in the non-dressy profession. Men in Luxembourg seem to suffer a wage penalty for being attractive. Naturally, it may be the case that good looking individuals are better qualified or have other desirable human capital traits and this is the main reason they obtain a higher wage. In the next section, we extend our analysis to control for these observable characteristics with both a simple selection model and a more flexible decomposition methodology.

\section{Methodology}

We first estimate a Heckman selection model for wages to identify the average effect of attractiveness and confidence on wages. Next, we use distribution regression (DR) to see how this changes across the wage distribution and to decompose the effect into a part attributable to characteristics and an unexplained part.

\footnotetext{
${ }^{6}$ Due to the availability of other exogenous variables we were able to omit experience from our wage equation in Germany. Neal and Johnson (1996) and others argue that such choice variables should be excluded when examining discrimination as they themselves may be affected by looks and confidence.
} 


\subsection{Empirical specification}

Our empirical model builds upon Hamermesh and Biddle (1994) (HB) and Mobius and Rosenblat (2006) (MR). Our wage function for individual $i$ is expressed in the following way:

$$
w_{i}=\beta_{0}+\beta_{1} x_{i}+\beta_{2} B_{i}+\beta_{2}^{\prime} C_{i}+\beta_{3} D_{i}+\beta_{4} B_{i} D_{i}+\beta_{4}^{\prime} C_{i} D_{i}+\varepsilon_{i}
$$

$B_{i}$ is a vector indicating whether individual $i$ is physically attractive or not; $C_{i}$ is a vector indicating whether individual $i$ is confident or not; $D_{i}$ is an indicator variable for whether person $i$ is in an occupation where looks could enhance productivity and zero otherwise (see Section 3.2 for the classification); $x_{i}$ is a vector of other individual level characteristics; and $\varepsilon_{i}$ is the error term.

The situation where we find a robust effect of beauty and/or confidence on earnings, independent of occupations $\left(\beta_{2}, \beta_{2}^{\prime}>0\right.$ and $\left.\beta_{3}=\beta_{3}^{\prime}=\beta_{4}=\beta_{4}^{\prime}=0\right)$ could be the result of employer discrimination or be a stereotype effect whereby attractiveness/confidence has raised the social and communication skills of good looking people ${ }^{7}$ and, as a result, raises employers estimates of workers productivity.

In the HB model, the occupational sorting hypotheses suggests that occupational requirements for beauty create independent effects on wages and, as a result, lead people to select certain occupations based on their looks and the expected returns to those looks. In our model $\beta_{3}, \beta_{3}^{\prime}>0$ can be interpreted as this occupational sorting, although it can also be an occupational premium independent of physical appearance.

Finally, workers may sort into occupations where attractiveness pays off $\left(\beta_{4}, \beta_{4}^{\prime}>0\right.$ and $\beta_{2}=\beta_{2}^{\prime}=\beta_{3}=\beta_{3}^{\prime}=0$ ). In this case, physical appearance or confidence therein may enhance the worker's ability to engage in productive interactions with coworkers or customers in certain occupations because they prefer interacting with better looking individuals. In this framework there will be a premium for good looks. Attractive and unattractive workers may be in the same occupation if the unattractive worker also has other productivity enhancing characteristics that affect the wage. This is known as customer discrimination in HB.

We use equation 1 as the basis of our empirical analysis. As a first step, we estimate the two-step model to correct for selection into work, separately for men and women. $P(E=1 \mid Z)=\Phi(Z \gamma)$ is the probability that an individual will be employed $(E=1$ if employed and 0 otherwise). $Z$ is a vector of characteristics that affect the probability of being employed and $\Phi$ is the cumulative normal distribution function. Then $w *$ is the potential wage and is not observed if $E=0$

$$
w *=Y \beta+u
$$

where $Y$ is a vector of characteristics influencing wages (such as company size, contract type, nationality, education, experience, public sector, occupation type, beauty and confidence). Then the expected wage, assuming that the error term in the selection equation, $\varepsilon$

\footnotetext{
${ }^{7}$ Research finds that teenagers with wage boosting physical characteristics have higher income as adults (e.g. height in Persico et al. (2004)) suggesting wage enhancing social skills, such as confidence are acquired even before individuals enter the labor market.
} 
and $u$, are jointly normal is

$$
E[w \mid Y, E=1]=Y \beta+E[u \mid Y, E=1]=Y \beta+\rho \sigma_{u} \lambda(Z \gamma)
$$

where $\rho$ is the correlation coefficient between $\varepsilon$ and $u ; \sigma_{u}$ is the standard deviation of $u$ and $\lambda(Z \gamma)$ is the Inverse Mills' Ratio $\left[\frac{\phi(.)}{\Phi(.)}\right]$ evaluated at $Z \gamma$. The equation tested is as follows:

$$
w_{i}=\beta_{0}+\beta_{1} x_{i}+\underbrace{\beta_{2}}_{\begin{array}{c}
\text { stereotype/ } \\
\text { employer } \\
\text { discrimination }
\end{array}} \theta_{i}+\underbrace{\beta_{3}}_{\begin{array}{c}
\text { occupational } \\
\text { effect }
\end{array}} D_{i}+\underbrace{\beta_{4}}_{\begin{array}{c}
\text { customer } \\
\text { discrimination } \\
\text { productivity }
\end{array}} \theta_{i} D_{i}+\underbrace{\rho \sigma_{u} \lambda(Z \gamma)}_{\begin{array}{c}
\text { selection } \\
\text { correction }
\end{array}}+\varepsilon_{i}
$$

where $\theta_{i}=B_{i}+\eta C_{i}$ and $\beta_{2} \eta=\beta_{2}^{\prime}$ from eq 1 .

\subsection{Distribution regression}

Given that there are reasons to believe that the effect of beauty may vary across the distribution, either because of varying occupational and productivity requirements across the distribution or because of differences in the effect of other social skills such as confidence, in the final econometric stage, we extend our analysis to the entire distribution of wages and decompose the effect of beauty/confidence on wages into a portion attributable to characteristic differences and a portion that is unexplained. We interpret this unexplained part as the beauty/confidence premium or penalty.

DR was pioneered by Foresi and Peracchi (1995) to model excess returns on financial markets. More recently, Chernozhukov et al. (2009) applied this methodology to examine the effect of labor market institutions on wage inequality in the U.S. See also Fortin et al. (2011) for more details on this and other decomposition methods for distributions. ${ }^{8}$ We are interested in the difference in the conditional distribution of wages for men and women of different classes of physical appearance/confidence, given explanatory variables, while holding the marginal distribution of these covariates constant. In practical terms, this involves running a series of probit models at each point in the wage distribution separately for men and women for each physical appearance and confidence group. The dependent variable is binary and takes the value of 1 if the individual has an hourly wage below $w$, where $w$ takes the value of each point of the wage distribution sequentially, and 0 otherwise. We predict the probability that an individual has an hourly wage below $w$ in the distribution, as well as predicting the counterfactual probability if they belonged to a different physical appearance/confidence group. We employ an OaxacaBlinder style decomposition (Oaxaca (1973), Blinder (1973)) to the marginal distributions of each physical appearance/confidence group to identify what the distribution of wages would be for men and women separately, in the absence of premia and penalties based on physical appearance/confidence. We can thus identify what portion of the wage gap

\footnotetext{
${ }^{8} \mathrm{DR}$ can be thought of as the flip-side of QR. While QR models the conditional wage at a particular location (e.g. the first quantile group, $p=0.1$ ) in the distribution, DR models the probability (between 0 and 1) of having a wage lower than a certain level. An advantage of DR, is the fact that, in contrast to QR, it can be simply extended to allow for selection correction. We do not exploit this in this paper as we do not find evidence of selection.
} 
between groups is due to different characteristics, and what part is unexplained and can, therefore, be attributed to attractiveness or confidence.

Starting from estimates of the conditional distribution of the wages of females or males $(s=m, f)$ with group characteristics $i$ ( $i=$ beautiful (b), plain (p), confident (c) and unconfident $(\mathrm{u})$ ), given human capital characteristics $(x)$, we recover estimates of the marginal distribution by integration of the conditional distributions over human capital characteristics:

$$
F_{s, i}^{s, i}(w)=\int_{\Omega_{x}} F^{s, i}(w \mid x) h_{s, i}(x) d x
$$

where $F^{s, i}(\cdot \mid x)$ is the conditional cumulative wage distribution function for human capital characteristics $x$ in group $i$ and $h_{s, i}$ is the density distribution of human capital characteristics for this group.

Separating marginal wage distributions and human capital distributions in this way allows us to define counterfactual wage distributions. For example, we can construct the counterfactual wage distribution of plain women if they were paid as beautiful women:

$$
F_{f, p}^{f, b}(w)=\int_{\Omega_{x}} F^{f, b}(w \mid x) h_{f, p}(x) d x
$$

where $F^{f, b}(\cdot \mid x)$ is the conditional cumulative wage distribution function for beautiful women with human capital characteristics $x$ and $h_{f, p}$ is the density distribution of human capital characteristics for plain women.

Estimates are obtained by replacing $F^{f, b}(\cdot \mid x)$ by estimates $\hat{F}^{f, b}(\cdot \mid x)$ in equation (6), and by averaging over our sample of $N$ plain female workers:

$$
\hat{F}_{f, p}^{f, b}(w)=\sum_{t=1}^{N_{f, p}} \hat{F}^{f, b}\left(w \mid x_{t}\right)
$$

Thus the wage gap between plain and beautiful (or unconfident and confident) individuals can be decomposed into a part attributable to characteristics and an unexplained part, which is the beauty or confidence premium/penalty and is due to different returns to characteristics for beautiful and plain individuals and for confident and not confident individuals. For example:

$$
F_{s, p}^{s, p}(w)-F_{s, b}^{s, b}(w)=\left[\hat{F}_{s, p}^{s, p}(w)-\hat{F}_{s, p}^{s, b}(w)\right]+\left[\hat{F}_{s, p}^{s, b}(w)-\hat{F}_{s, b}^{s, b}(w)\right]
$$

The first expression on the right hand side of equation 8 identifies the unexplained difference between plain and beautiful individuals' wage distributions. A positive value would indicate that there is a premium to being beautiful at wage $w$. The second expression identifies the characteristic effect, which gives the difference in the marginal distribution that is due to the fact that beautiful and plain individuals have different human capital characteristics. A positive value would indicate that beautiful individuals have better human capital and labor market characteristics than plain individuals since they have a lower probability of having a wage below $w$. We perform this decomposition analogously for 
unconfident and confident individuals.

\section{Empirical Results}

In the first instance, we examine the determinants of earnings and check for selection in our model. Next, we test our model described in Section 4. Finally, we use DR techniques to identify the characteristic and unexplained gaps across the distribution.

\subsection{Mean effects of beauty and confidence}

Tables 3 to 6 provide results on the selection model for women and men with beauty and confidence measures and on the testing of equation (1), first for Germany and then Luxembourg. First, we look at the estimation results of the selection equation (columns (3), (6) and (9)). We see that married women and people with bad health are less likely to work. Age has the traditional positive effect on work for both sexes at a decreasing rate and the number of children has a negative effect on labor supply in both countries. In Germany, we find that the "old-fashioned" variable (Do you believe a woman's place is in the home?) has a strong negative effect on the work decision for women while a working spouse has a significant effect on the working decision of men. In both countries, $\rho$ is not significantly different from zero and the low $\chi^{2}$ implies that there is no correlation across the selection probit and wage equation, suggesting that we do not need to worry about having biased estimates if we do not control for selection. We have also included a model without selection in the first column and we find the coefficients to be almost identical in both models and the $R^{2}$ to be in the range of $0.25-0.27$ for Germany and $0.57-0.63$ for Luxembourg in the models without selection correction.

When we look at the direct effects of covariates in the wage equation, we find that marital status has no significant effect on women's wages (only on the decision to work). High education, experience (in Luxembourg), working for a big company and being a civil servant have the expected positive effects in both countries. Having a temporary work contract has a diminishing effect on wages in Luxembourg (not available in Germany). We find that working part-time has a positive effect on hourly wages (particularly for women). In Luxembourg, both male and female Portuguese immigrants and other nonnatives have a disadvantage in the labor market. ${ }^{9}$ We do not find this to be the case in Germany.

As discussed in Section 3 and Table 2, raw differences indicate that there exists a statistically significant wage penalty for plain workers. When we control for demographic and labor market characteristics, we still find this to be the case in Germany. In Table 3 we find a $25 \%$ premium for beautiful women $(\operatorname{col}(2))$ and a $17 \%$ premium for confident women in Germany. For men, the effect is a little smaller: $16 \%$ premium for beauty and no significant effect for confidence. However, when we control for both beauty and confidence (col(8)), confidence becomes insignificant for men and women, indicating that it is predominantly through the objective beauty channel that physical appearance affects

\footnotetext{
${ }^{9}$ Over $40 \%$ of the population in Luxembourg is foreign born with $16.2 \%$ born in Portugal. The immigrant population is an interesting mix of either very low or very high qualified individuals. For a comparative perspective of immigrants in Luxembourg see Mathae et al. (2011).
} 
wages. In Luxembourg, the effect of beauty and confidence on wages is smaller and insignificant. As the Luxembourgish data contains only one of either beauty or confidence for each observation, we cannot control for both simultaneously. ${ }^{10}$

Customers may prefer interacting with better looking or more confident individuals employed in certain occupations. In our model this effect is seen in the coefficients on the interaction terms between beauty/confidence and 'dressy' occupations (our $\beta_{4}$ and $\beta_{4}^{\prime}$ from equation (3)). We find the effect for beauty to be negative and statistically significant only for women indicating that, for women, beauty does not pay off in occupations that require more personal interactions. The interaction is also negative, but not significant for men. In Luxembourg it is positive, but insignificant for both.

Finally, we examine whether or not there is occupational sorting (our $\beta_{3}$ ). The coefficient on the dressy variable is positive and significant for all our specifications for women and for men. The effect is a stronger in Germany than in Luxembourg $(26 \%-32 \%$ versus $16 \%-20 \%$ ) indicating that there are higher wages in occuptions where beauty is deemed more important in both countries. However, as discussed previously, these may simply be higher paying occupations independently of beauty requirements.

In the next section, we compare these effects across the distribution in the two countries.

\subsection{Distributional effects of beauty and confidence}

Tables 7 and 8 show the coefficients from distribution regression of the hourly wage at one point in the distribution, the median. The explanatory variables used to model wages are identical to those used in the mean regressions. Importantly, we include confidence as a regressor when we model wages by physical appearance category and we use beauty as a regressor when modelling wages by confidence category. The interpretation of these coefficients is similar to a probit model. For example, the negative coefficient on married in (col(1)) of table 7 indicates that married men within the "plain" group are less likely to be located in the lower half of the wage distribution, that it, marriage has the typically positive effect on wages for this group.

Figure 1 shows the marginal wage distributions of each of the groups of workers in both countries. $^{11}$ Looking first to the left-hand side graphs, which depict the Luxembourg wage distributions, we note that, within beauty categories, plain men earn the most, followed by beautiful men, beautiful women and, finally, plain women. Within confidence categories, confident men earn the most, followed by unconfident men and confident and unconfident women (whose wage distributions are very close). We see a slightly different picture for Germany. Within beauty categories, beautiful men earn the most, followed by plain men, beautiful women and plain women. Within confidence categories, the ordering is unconfident men, confident men, confident women and unconfident women. In both

\footnotetext{
${ }^{10}$ Recall that the Luxembourg questionnaire contains information about self-assessed beauty, i.e. confidence, but that a number of these questions were answered by someone other than the individual (proxy respondants) and these observations form a crude group of people for whom we have an objective measure of beauty

${ }^{11}$ To test the model elaborated in Section 4 using the DR methodology, we plot the predicted distribution of wages for each country against the actual distribution and find an excellent fit for our model (results available upon request).
} 
countries, the difference in distributions by beauty categories is larger than the difference in distributions by confidence categories.

\subsubsection{Decomposition: an example}

In Figure 2, we provide a graphical example of how the marginal distributions illustrated in Figure 1 are decomposed into the part due to characteristics and the unexplained part, as outlined mathematically in equation $8 . \hat{F}_{f, b}^{f, b}(w)$, the marginal wage distribution of beautiful women, is represented by the line "Beautiful women". The marginal wage distribution

of plain women $\hat{F}_{f, p}^{f, p}(w)$ is represented by the line"Plain women" while $\hat{F}_{f, p}^{f, b}(w)$, "Plain women paid as beautiful women" shows the counterfactual wage distribution of plain women, rewarded for their characteristics in the same way as are beautiful women. The vertical difference between the "Plain women" and the "Plain women paid as beautiful women" curves depicts the difference in wage distributions that is unexplained and can be attributed to beauty. The difference between the "Plain women paid as beautiful women" and "Beautiful women" curves gives the difference in distribution that is accounted for by observed characteristics (such as education, age, etc.). In this example, it is clear that the characteristic gap dominates at the bottom of the distribution while the unexplained gap is more prominent around the middle of the wage distribution. In the next section, for a clearer exposition, we plot the differences between these curves, rather than the curves themselves.

\subsection{Explained and unexplained wage differences across the distribution}

In figures 3 and 4 we plot a set of characteristic and unexplained differences in distributions for women and men, decomposing the wage distributions as explained in the previous section. We compare the results for the two countries to have a better understanding of cross-national differences.

In Figure 3 we see that the wage premium for females in Germany is located at the bottom of the distribution and peaks at around 7ppt. The beauty premium for females in Luxembourg is much larger and is also seen toward the bottom half of the distribution. The characteristics gap in Germany indicates that attractive females have better labor market characteristics than unattractive females, particularly at the bottom of the distribution. In Luxembourg, attractive females have worse characteristics than unattractive females at the bottom of the distribution, although this trend is reversed further up in the distribution. For men, we find that beauty has an ambiguous effect on wages in Luxembourg, but a very large positive effect in Germany, with the beauty premium approaching $15 \mathrm{ppt}$ toward the middle of the distribution. In Luxembourg, attractive men have worse labor market characteristics than unattractive men, while there is no characteristic gap for men in Germany implying, thus, that differences between the wage distribution of attractive and unattractive men are all unexplained.

When it comes to confidence, the upper left hand panel in in Figure 4 shows that, while there is no clear premium or penalty for confident women in Luxembourg, there is a penalty for confident women in Germany in the bottom half of the wage distribution, peaking at around 5ppt. This means that confident women are 5ppt more likely to earn 
less than average wages than unconfident women with similar characteristics. The characteristic gap between confident and unconfident women is ambiguous in Luxembourg and positive at the bottom of the distribution in Germany, meaning that confident women have better characteristics than less confident women at the bottom of the wage distribution in Germany. The confidence effect for men in Luxembourg is ambiguous across the distribution while the confidence effect for German men, like German women, is negative and larger than the latter throughout the distribution. However, confident German men have worse characteristics than their less confident counterparts at the bottom of the wage distribution, while the reverse is true in Luxembourg throughout the distribution.

Trusting the objective beauty measure from the German data more than that from the Luxembourg data, we base our conclusions relating to beauty on this country. We find a beauty premium for both women and men, although that for women is concentrated in the lower half of the wage distribution and is smaller than that for men. Basing our conclusions about confidence on results from both countries, we find that confidence affects wages ambiguously across the wage distribution in Luxembourg but that there are penalties for confidence in Germany, especially for men.

\subsection{A comparison}

As suspected, differences exist in the beauty premium estimated using traditional methods (in section 5.1) and those estimated across the wage distribution using decomposition techniques. Evaluating the effect of beauty on wages at the mean, we find that women experience a larger beauty premium (20\% in Germany, $10 \%$ in Luxembourg) than men (14\% in Germany, $-3 \%$ in Luxembourg). However, when we use decomposition techniques to isolate the portion of the beauty premium that is due to different characteristics between groups, we find that, in Germany, attractive men experience a larger unexplained wage premium than women (see Figure 3). Much of the beauty premium for women, identified using simple regressions, is therefore due to the characteristic gap between attractive and unattractive women (seen in the top right panel of Figure 3). In Luxembourg, the characteristic gap is negative for men, and negative to positive for women as we look across the wage distribution. In the case of women, the characteristic gap works in the opposite direction to the unexplained gap throughout the distribution so that failure to decompose the beauty premium into these two components gives misleading results. For men in Luxembourg, the characteristic gap is negative throughout the distribtution and larger than the unexplained gap, which results in an overall beauty penalty when we use simple regression. In every case, the characteristic and unexplained gaps are larger at the bottom of the wage distribution than at the top, reinforcing the importance of looking at these effects in a distributional context.

\section{Robustness checks}

As explained in Section 3, the self reported measures that we use to proxy confidence may be endogenous if people feel more confident or beautiful when they earn more. While it is interesting to see how these self-reported measures compare against objective measures in Figures 3 and 4, we may not be able to draw any causal inference from them. Therefore next we check the robustness of the objective beauty measure results in Germany. 
Figure 5 presents the decomposition of the marginal wage distributions in Germany into a characteristic effect and an unexplained (beauty) effect with fitted 95\% confidence intervals. ${ }^{12}$ The small beauty effect observed for women at the bottom of the wage distribution is statistically insignificant, while the beauty premium for men is statistically significant throughout the distribution. Additionally, the small positive characteristic effect observed for women is significant at the bottom of the wage distribuition.

As outlined in Section 4.1 our framework suggested the existence of occupational sorting whereby looks could enhance productivity and yield a positive effect on wages. To check this prediction, we present results from an additional specification. We retain only those who work in the "dressy" profession and rerun our analysis using the distribution regression framework. If sorting is taking place, individuals with less desirable physical appearance characteristics but higher other labor market attributes and those with desirable physical appearance characteristics but lower other labor market attributes can be expected to sort into "dressy" professions. In both cases, we would expect to see a downward movement of the characteristic gap. Looking at Figure 6, we see that the characteristic gap has gone from positive to zero for women at the bottom of the distribution and from zero to negative for men at the bottom of the distribution. This is in line with our expectations as there are either relatively more ill qualified attractive people or more highly qualified unattractive people in the dressy profession. Whichever is the case, this provides evidence of occupational sorting, based on physical appearance, at the bottom of the wage distribution.

In a further analysis, we restrict the sample to young (18-45 year old) people, whose physical appearance may be more important in the labor market (Figure 7). For young men, we find that the beauty premium is slightly smaller than that of the whole sample (peaking at around 12ppt) and it is more localised at the bottom of the wage distribution. The beauty premium for young women is larger than that of the whole sample (at around $11 \mathrm{ppt}$ at the bottom of the distribution) but is, once again, concentrated around the bottom of the wage distribution. It seems that, similar to what has been suggested for the AngloSaxon countries, beauty influences the wages of young women more and young men less than the older cohort. However, due to the small sample size of the younger groups, we see large confidence intervals. This issue could be alleviated and the results strengthened with a larger sample size.

\section{Conclusions}

Using data from two countries and various techniques, we show that the effect of beauty varies across the distribution and that mean techniques can provide misleading information as opposing effects may cancel each other out. We also demonstrate that differences in observable characteristics between attractive and unattractive people can lead to erroneous estimates of the effect of beauty on wages using traditional methods.

Given the opportunity of using unique data sets, which contain both subjective and objective measures of beauty, we find that the effect of beauty on wages dominates the effect of

\footnotetext{
${ }^{12}$ The confidence intervals are constructed using the point estimates $+/-1.96$ standard deviations calculated from 250 draws at the individual level.
} 
confidence. There is a beauty premium at the bottom of the wage distribution for women and throughout the distribution for men. A similar average result has been found for Australia (Leigh and Borland (2012)), while results from the U.S./Canada tend to find larger (or similar) premia for women than men. The effect of confidence is ambiguous or negative for both women and men across the distribution. This is a new result as both Hamermesh and Biddle (1994), for the U.S. and Canada, and Mobius and Rosenblat (2006) for Argentina, find some evidence of confidence wage premia. However, as we find characteristic gaps between confident and unconfident women and men (with confident people having better labor market characteristics for the most part), this result is unsurprising. Indeed, our estimation of mean effects would suggest a positive (although) insigificant effect of confidence on wages for both men and women. Decomposition techniques show that this positive effect is largely due to observable characteristic differences between the two groups.

Restricting our sample to those working in professions where beauty is deemed more important, we find evidence of occupational sorting by beauty requirements and, restricting our sample to the young $(<45)$, we find preliminary evidence that beauty may be more related to wages for young women than older women. The availability of a larger sample for the young would allow further research about the effects of beauty on wages for this group, in particular.

By constructing counterfactual distributions using DR, we find that much of the wage penalties observed in the Hamermesh and Biddle (1994) model are due to the different characteristics of people in different physical appearance classes, and only a small portion is actually unexplained and may be attributed to discrimination. The DR method, which is largely unused in this literature, provides a straight forward manner in which to decompose wage distributions into explained and unexplained components, if we suspect the effect of varying across the distribution.

\section{References}

Biddle, J. E. and Hamermesh, D. S. (1998). Beauty, Productivity, and Discrimination: Lawyers' Looks and Lucre. Journal of Labor Economics, 16(1):172-201. 3, 4

Blinder, A. S. (1973). Wage discrimination: Reduced form and structural estimates. The Journal of Human Resources, 8(4):pp. 436-455. 9

Bonjour, D. and Gerfin, M. (2001). The unequal distribution of unequal pay - An empirical analysis of the gender wage gap in Switzerland. Empirical Economics, 26(2):407427. 3

Chernozhukov, V., Fernandez-Val, I., and Melly, B. (2009). Inference on counterfactual distributions. CeMMAP working papers CWP09/09, Centre for Microdata Methods and Practice, Institute for Fiscal Studies. 9

Doorley, K. and Sierminska, E. (2011). Beauty and the beast in the labor market: Evidence from a distribution regression approach. CEPS/INSTEAD Working Paper Series 2011-62, CEPS/INSTEAD. 6 
Feingold, A. (1992). Good-looking people are not what we think. Psychological Bulletin, 111(2):304-41. 3

Foresi, S. and Peracchi, F. (1995). The Conditional Distribution of Excess Returns: An Empirical Analysis. Journal of the American Statistical Association, 90(430):pp. 451466. 9

Fortin, N., Lemieux, T., and Firpo, S. (2011). Decomposition Methods in Economics, volume 4 of Handbook of Labor Economics, chapter 1, pages 1-102. Elsevier. 9

French, M. T. (2002). Physical appearance and earnings: further evidence. Applied Economics, 34:569-572. 4

Hamermesh, D. S. (2011). Beauty Pays: Why attractive people are more successful. Princeton University Press. 4

Hamermesh, D. S. (2012). Tall or Taller, Pretty or Prettier: Is Discrimination Absolute or Relative? Working Paper 18123, National Bureau of Economic Research. 5

Hamermesh, D. S. and Biddle, J. E. (1994). Beauty and the Labor Market. American Economic Review, 84(5):1174-94. 3, 5, 6, 8, 16

Hamermesh, D. S., Meng, X., and Zhang, J. (2002). Dress for success-does primping pay? Labour Economics, 9(3):361-373. 3, 4

Harper, B. (2000). Beauty, Stature and the Labour Market: A British Cohort Study. Oxford Bulletin of Economics and Statistics, 62:771-800. 3, 4

Jackson, L. (1992). Physical attractiveness: A sociocultural perspective. New York: Guilford. 4

Leigh, A. and Borland, J. (2012). Unpacking the beauty premium: What channels does it operate through, and has it changed over time?? 4, 16

Lopez Boo, F., Rossi, M. A., and Urzua, S. (2012). The labor market return to an attractive face: Evidence from a field experiment. IZA Discussion Papers 6356, Institute for the Study of Labor (IZA). 5

Marlowe, C., Schneider, S., and Carnot, N. (1996). Gender and attractiveness biases in hiring decisions: are more experienced managers less biased? Journal of Applied Psychology, 81(1):11-21. 5

Mathae, T. Y., Porpiglia, A., and Sierminska, E. (2011). The immigrant/native wealth gap in Germany, Italy and Luxembourg. Working Paper Series 1302, European Central Bank. 11

Mobius, M. M. and Rosenblat, T. S. (2006). Why beauty matters. American Economic Review, 96(1)(5):222-35. 3, 4, 5, 8, 16

Mocan, N. and Tekin, E. (2010). Ugly criminals. The Review of Economics and Statistics, Vol. 92, No. 1:Pages 15-30. 5 
Neal, D. A. and Johnson, W. R. (1996). The role of premarket factors in black-white wage differences. Journal of Political Economy, 104(5):869-95. 7

Oaxaca, R. (1973). Male-female wage differentials in urban labor markets. International Economic Review, 14(3):693-709. 9

Persico, N., Postlewaite, A., and Silverman, D. (2004). The effect of adolescent experience on labor market outcomes: The case of height. Journal of Political Economy, 112:1019-1053. 3, 8

Sachsida, A., Dornelles, A. C., and Mesquita, C. W. (2003). Beauty and the labor market - study one specific occupation. 4

Sen, A., Voia, M.-C., and Woolley, F. R. (2010). Hot or not: How appearance affects earnings and productivity in academia. Carleton Economic Papers 10-07, Carleton University, Department of Economics. 3, 4

Watkins, L. and Johnston, L. (2000). Screening job applicants: The impact of physical attractiveness and application quality. International Journal of Selection and Assessment, 8(2):76-84. 5

\section{Tables and Figures}


Table 1: A comparison of the beauty and confidence measures for women and men and the perceived importance of beauty in Germany and Luxembourg.

Panel A

\begin{tabular}{lccc}
\hline \hline Luxembourg & Women & Men & diff \\
\hline Share in each category & & & \\
Beautiful & 0.534 & 0.529 & 0.005 \\
Plain & 0.466 & 0.471 & -0.005 \\
Confident & 0.436 & 0.450 & -0.014 \\
Unconfident & 0.564 & 0.550 & 0.014 \\
\hline Germany & & & \\
\hline Share in each category & & & \\
Beautiful & 0.593 & 0.540 & $0.053^{* * *}$ \\
Plain & 0.407 & 0.460 & $-0.053^{* * *}$ \\
Confident & 0.603 & 0.574 & 0.029 \\
Unconfident & 0.397 & 0.426 & -0.029 \\
\hline \hline Panel B & & & \\
\hline \hline Luxembourg & Non-dressy & Dressy & diff \\
\hline Perceived importance of beauty: & & & \\
All & 1.795 & 1.959 & $-0.164^{* * *}$ \\
Women & 1.806 & 2.041 & $-0.235^{* * *}$ \\
Men & 1.789 & 1.869 & $-0.080^{* *}$ \\
\hline \hline Perceived importance of beauty is 1-4 variable with 1: very important and 4: not important
\end{tabular}

Perceived importance of beauty is 1-4 variable with 1: very important and 4: not important

Source: 2008 GSS, 2007 PSELL; t statistics in parentheses * $\mathrm{p}<0.1 * * \mathrm{p}<0.05 * * * \mathrm{p}<0.01$ 
Table 2: Select wage differences statistics for beauty and confidence categories and by occupation (in Euros).

\begin{tabular}{|c|c|c|c|}
\hline Germany beauty & Above & Under & diff \\
\hline All & 10.974 & 9.184 & $1.790^{* * *}$ \\
\hline Women & 9.621 & 8.347 & $1.274^{* *}$ \\
\hline Men & 12.215 & 9.740 & $2.476^{* *}$ \\
\hline Women: Dressy & 9.884 & 9.367 & 0.517 \\
\hline Men: Dressy & 13.243 & 12.099 & 1.144 \\
\hline Women: Non-dressy & 8.592 & 6.111 & $2.481^{* * *}$ \\
\hline Men: Non-Dressy & 11.359 & 8.176 & $3.183^{*}$ \\
\hline Germany confidence & Above & Under & diff \\
\hline All & 10.555 & 9.891 & 0.664 \\
\hline Women & 9.619 & 8.410 & $1.208^{* *}$ \\
\hline Men & 11.394 & 10.932 & 0.462 \\
\hline Women: Dressy & 10.057 & 9.099 & 0.958 \\
\hline Men: Dressy & 12.428 & 13.639 & -1.211 \\
\hline Women: Non-dressy & 8.128 & 6.620 & $1.508^{*}$ \\
\hline Men: Non-Dressy & 10.503 & 9.163 & 1.341 \\
\hline Luxembourg confidence & Above & Under & diff \\
\hline All & 16.093 & 16.225 & -0.133 \\
\hline Women & 14.973 & 15.785 & -0.812 \\
\hline Men & 17.087 & 16.610 & 0.478 \\
\hline Women: Dressy & 16.929 & 18.118 & -1.189 \\
\hline Men: Dressy & 20.402 & 21.202 & -0.800 \\
\hline Women: Non-Dressy & 8.436 & 9.386 & -0.949 \\
\hline Men: Non-Dressy & 10.861 & 11.170 & -0.309 \\
\hline Luxembourg beauty & Above & 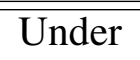 & 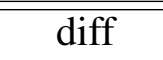 \\
\hline All & 14.531 & 15.713 & -1.182 \\
\hline Women & 12.973 & 11.519 & 1.454 \\
\hline Men & 15.051 & 17.050 & $-1.999^{* *}$ \\
\hline Women: Dressy & 14.239 & 13.842 & 0.397 \\
\hline Men: Dressy & 19.744 & 21.999 & $-2.255^{*}$ \\
\hline Women: Non-Dressy & 8.416 & 7.945 & 0.471 \\
\hline Men: Non-Dressy & 10.150 & 10.985 & -0.835 \\
\hline
\end{tabular}




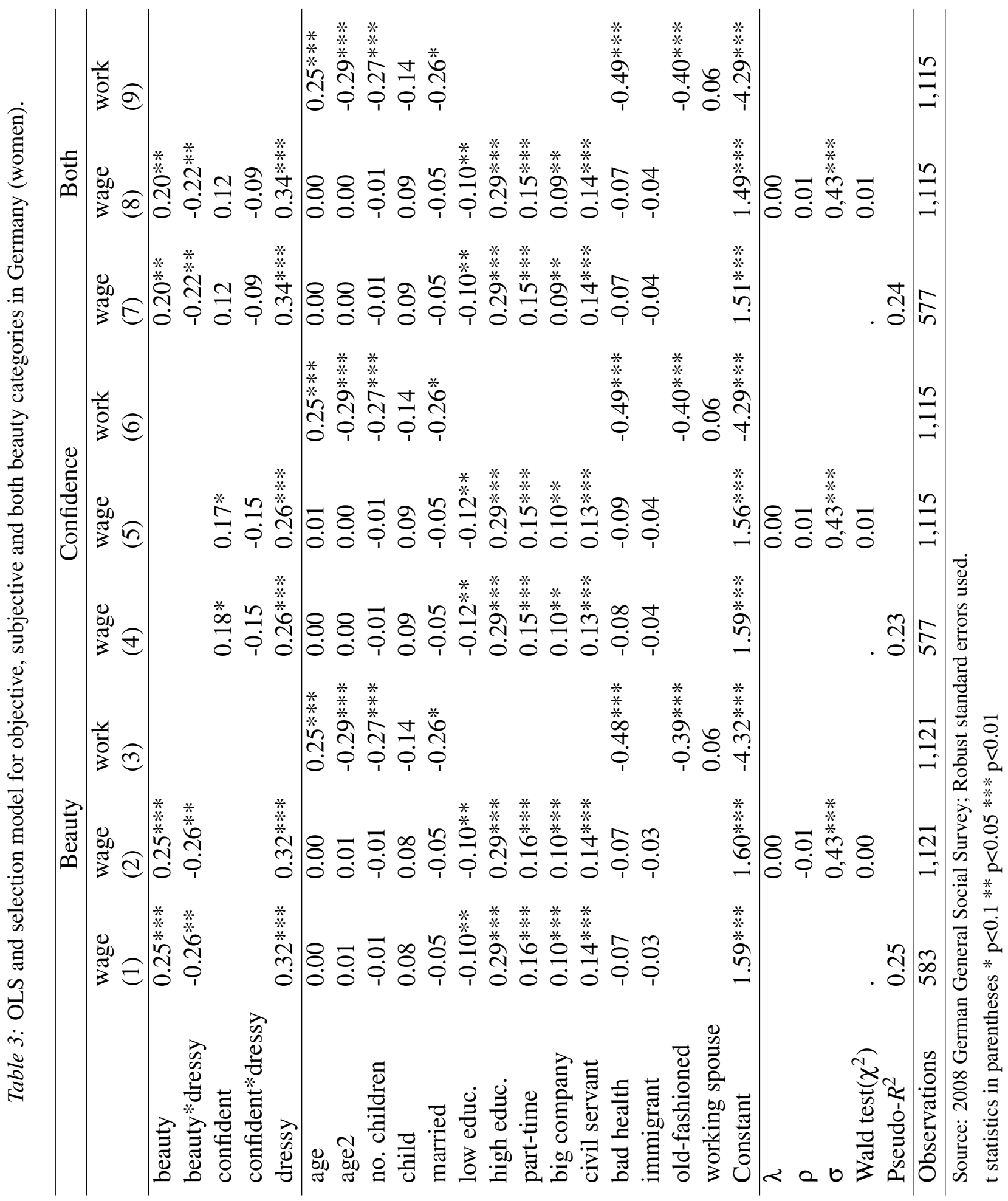




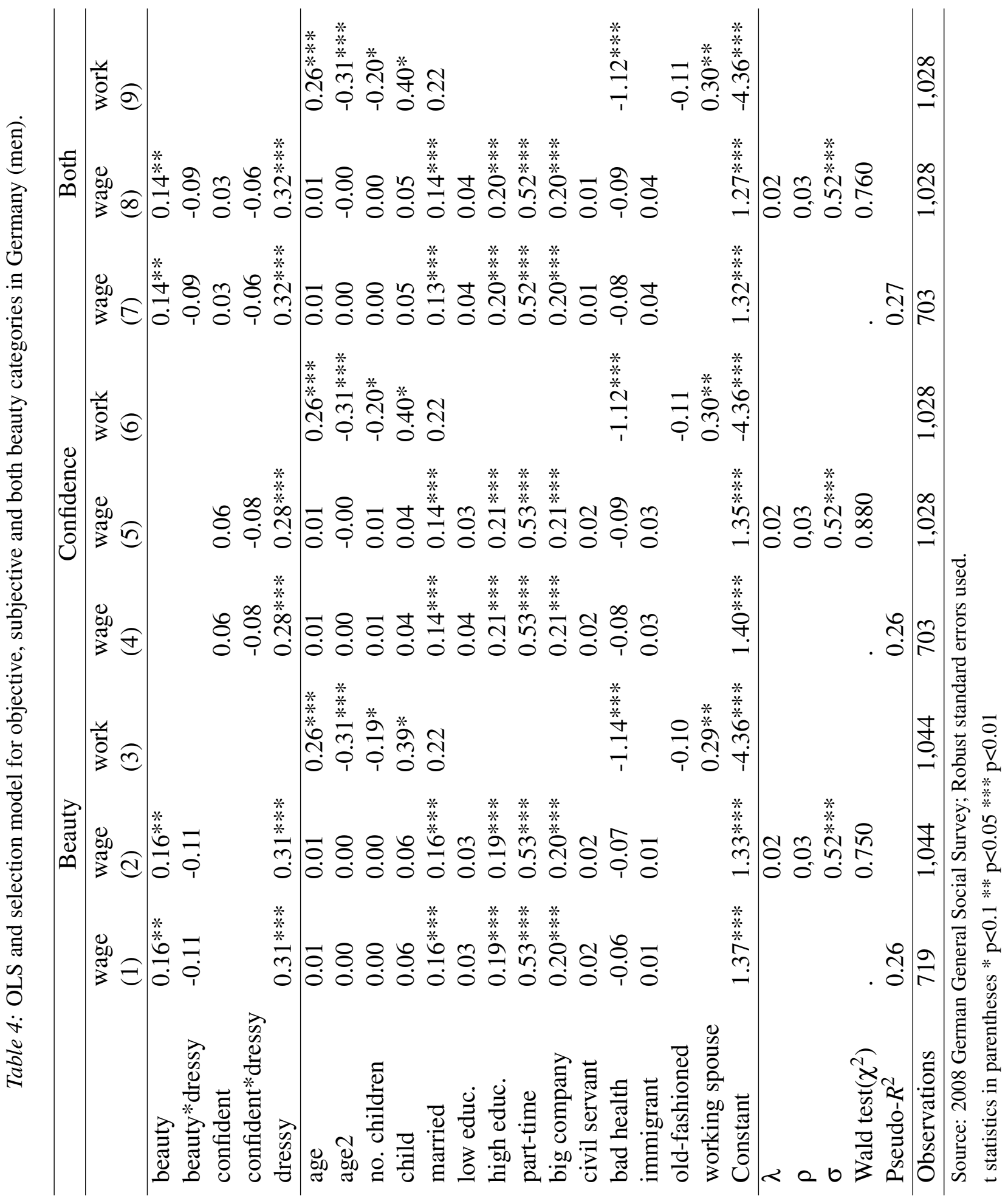




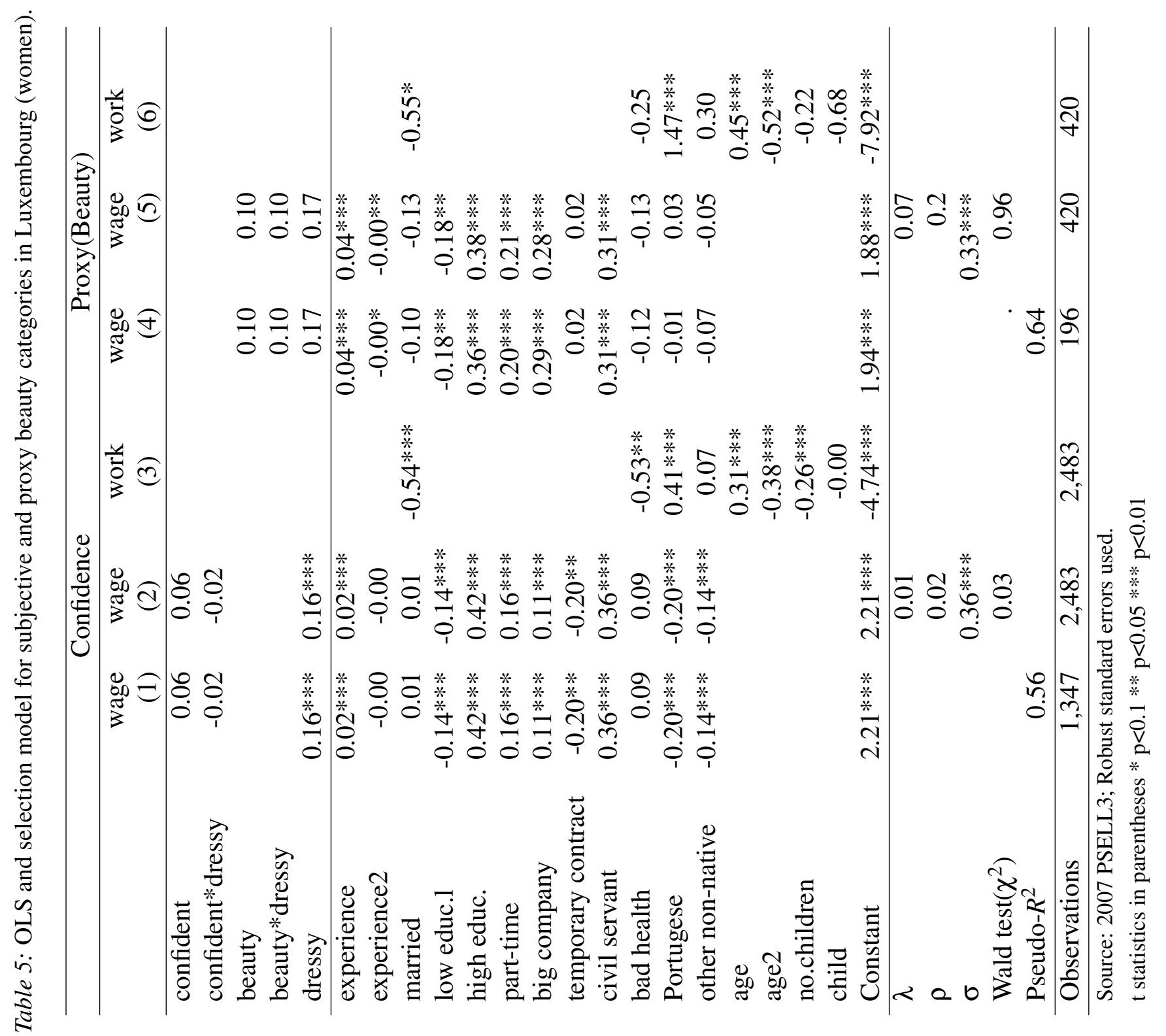




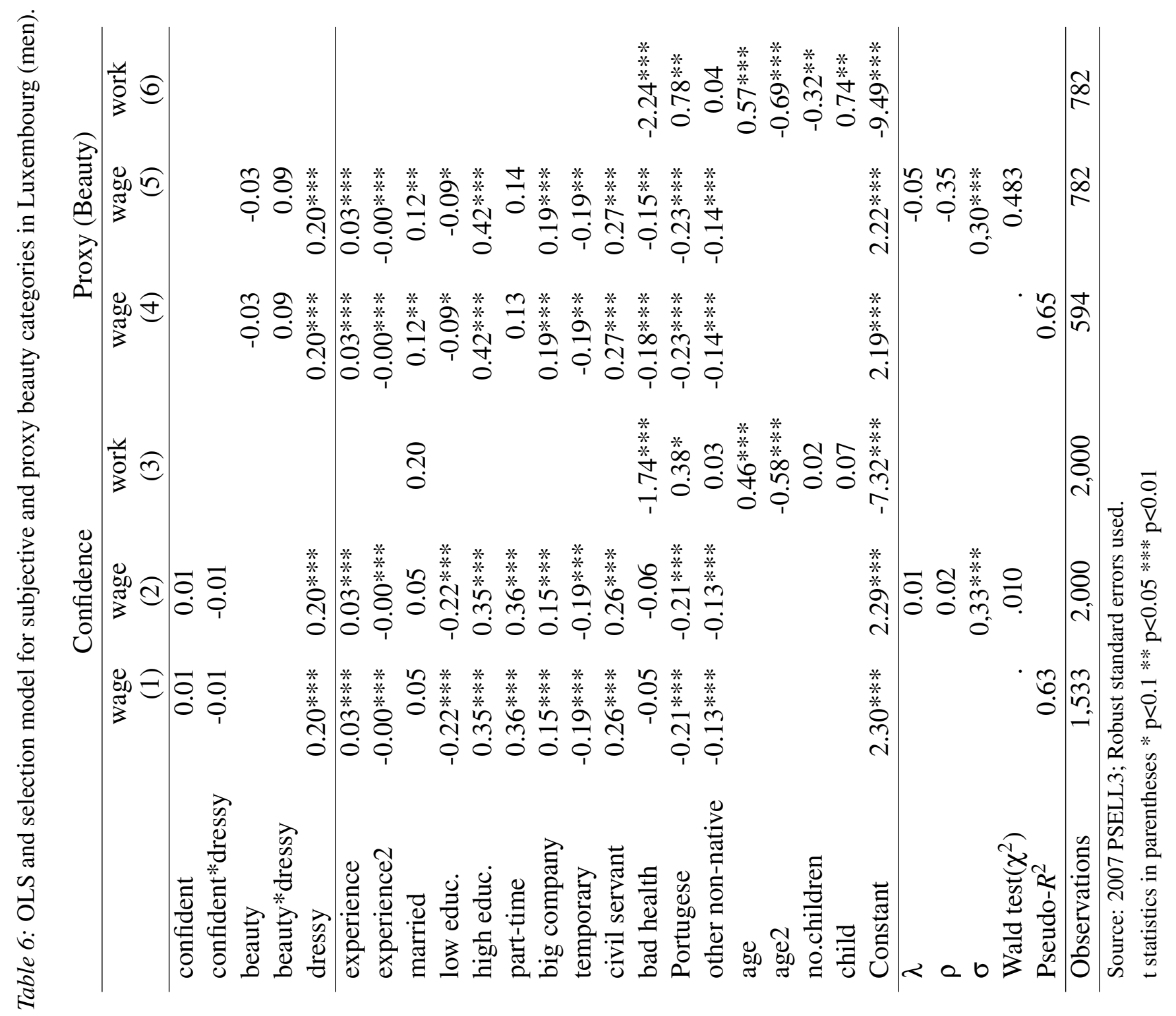




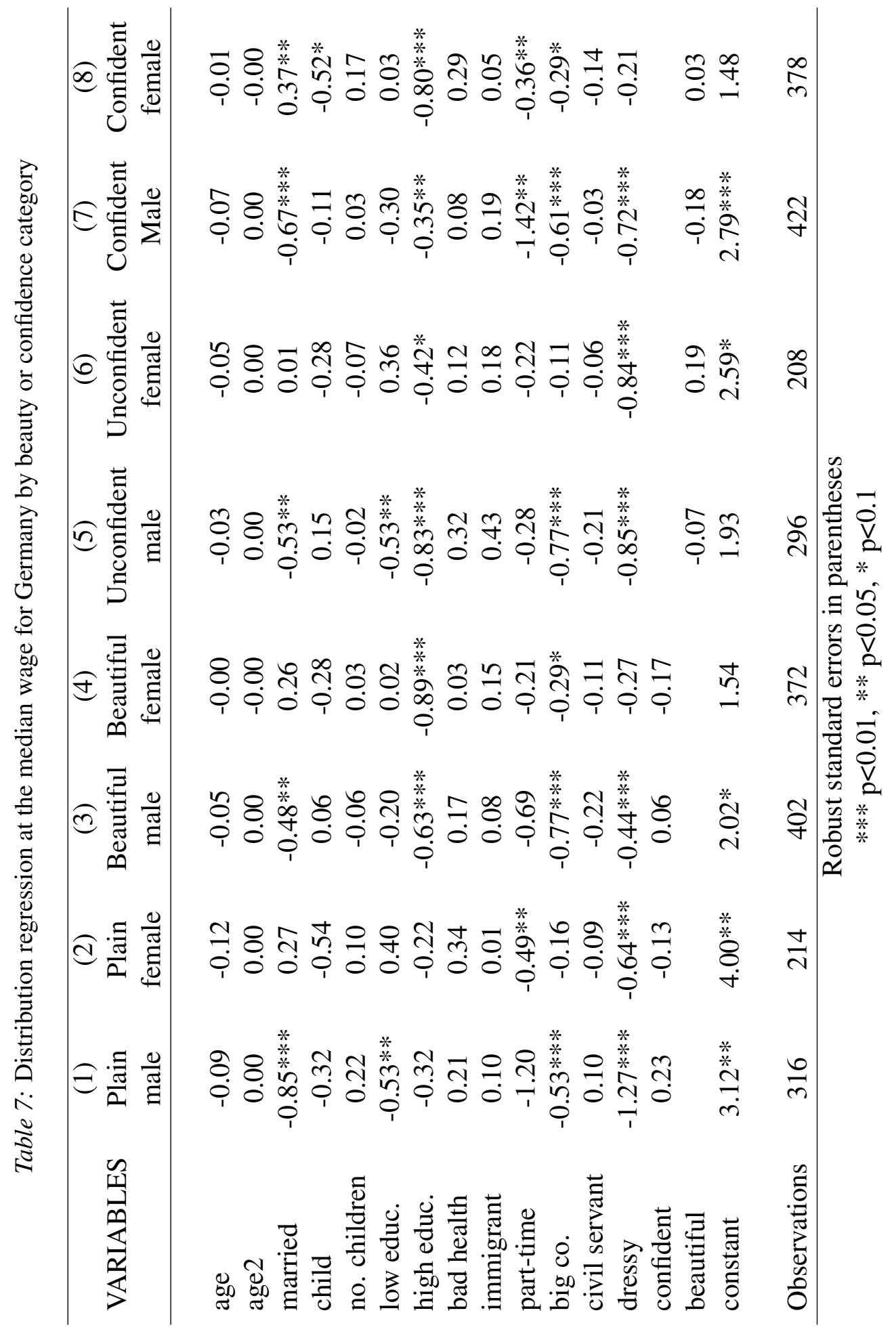




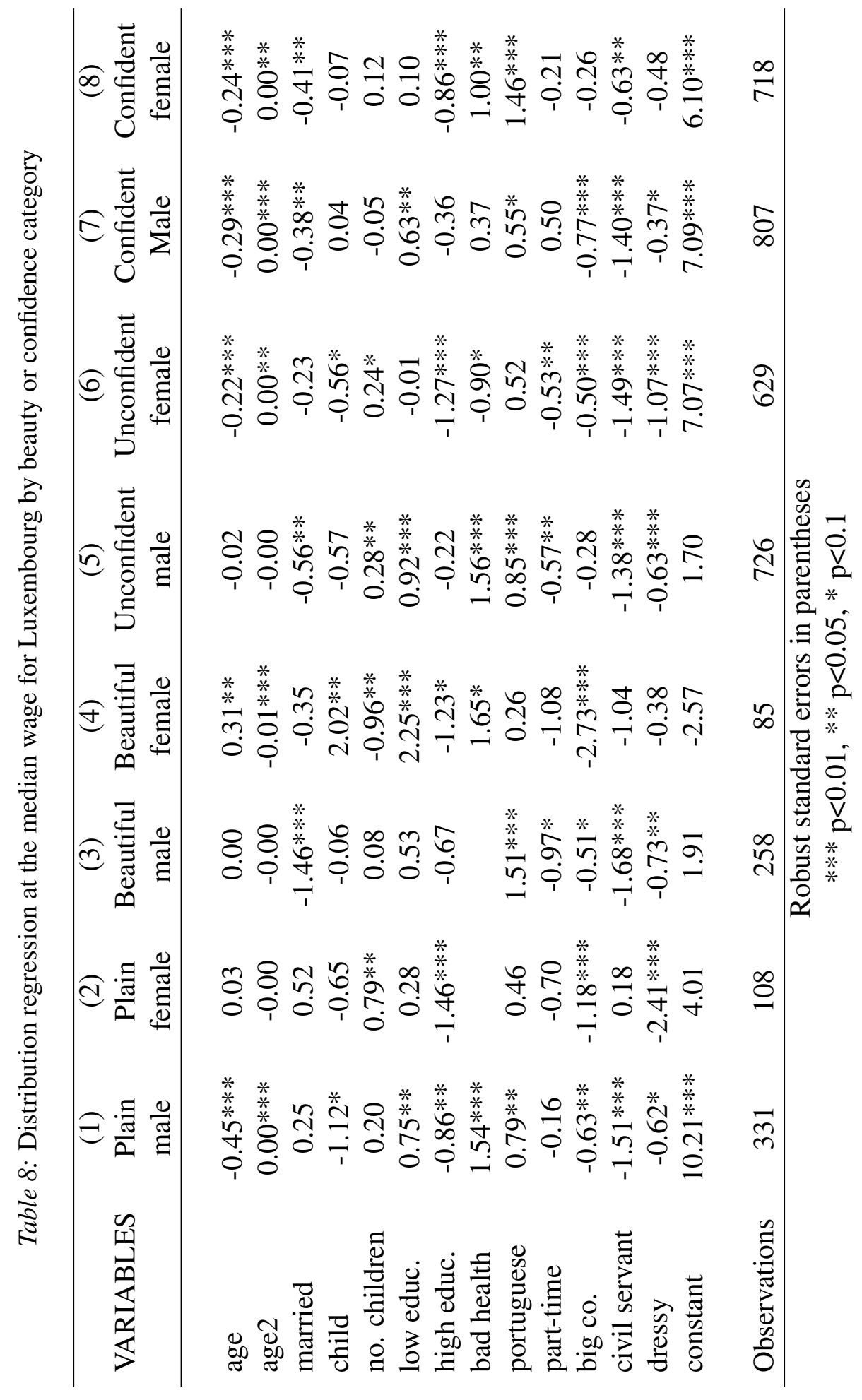




\section{Figure 1 Marginal wage distribution functions}
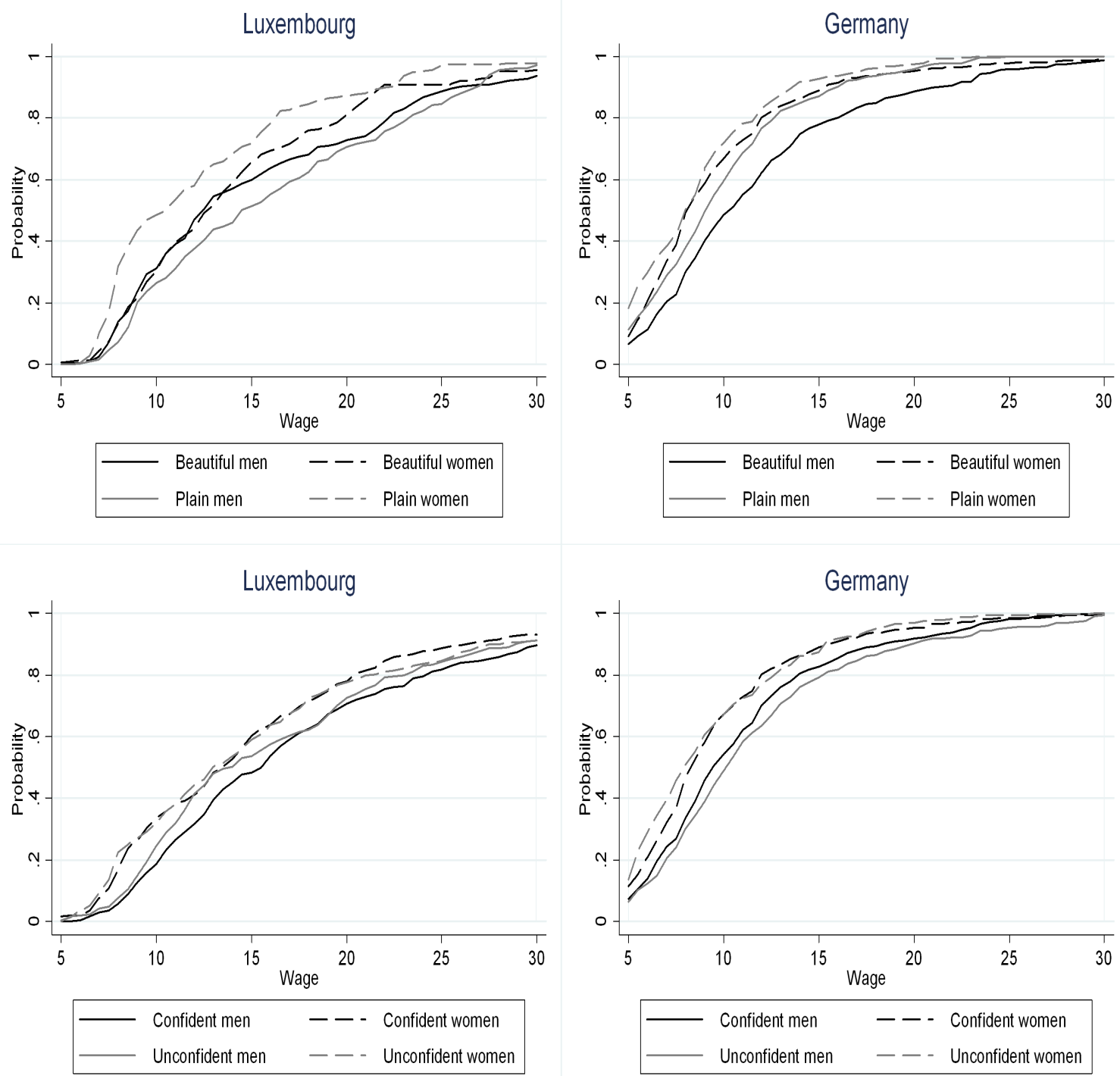

Note: Predicted marginal wage distributions for men and women grouped by beauty and confidence in Germany and Luxembourg Source: 2008 GSS; 2007 PSELL3 
$\overline{\text { Figure } 2 \text { Marginal and counterfactual wage distributions for beautiful and plain women }}$ in Germany.

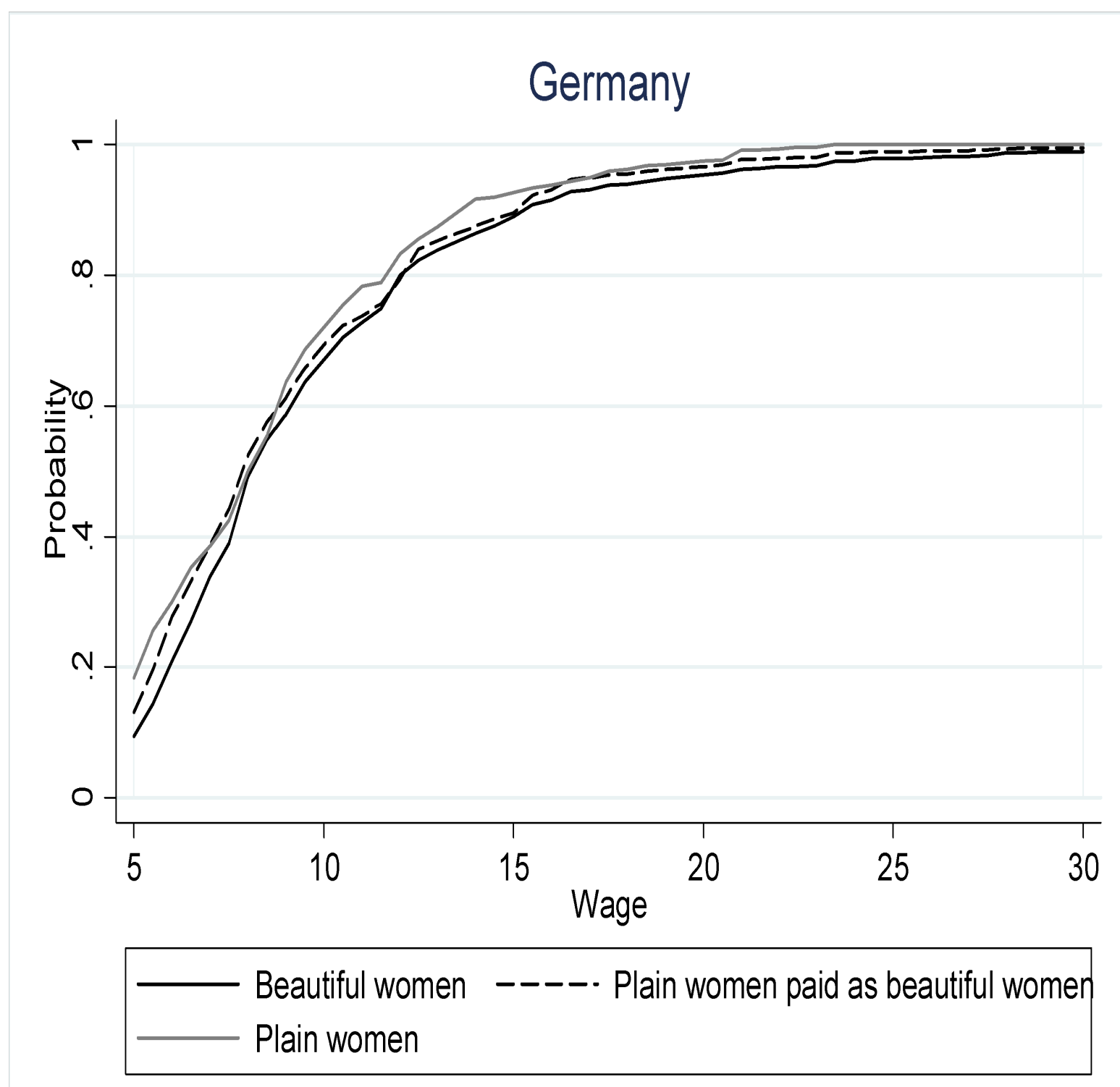

Note: The difference between the "Plain women" and "Plain women paid as beautiful women" curves gives the unexplained gap. The difference between the "Plain women paid as beautiful women" and "Beautiful women" curves gives the characteristic gap. Source: 2008 GSS 
Figure 3 Unexplained and characteristics gaps between plain and beautiful women and men across the wage distribution.
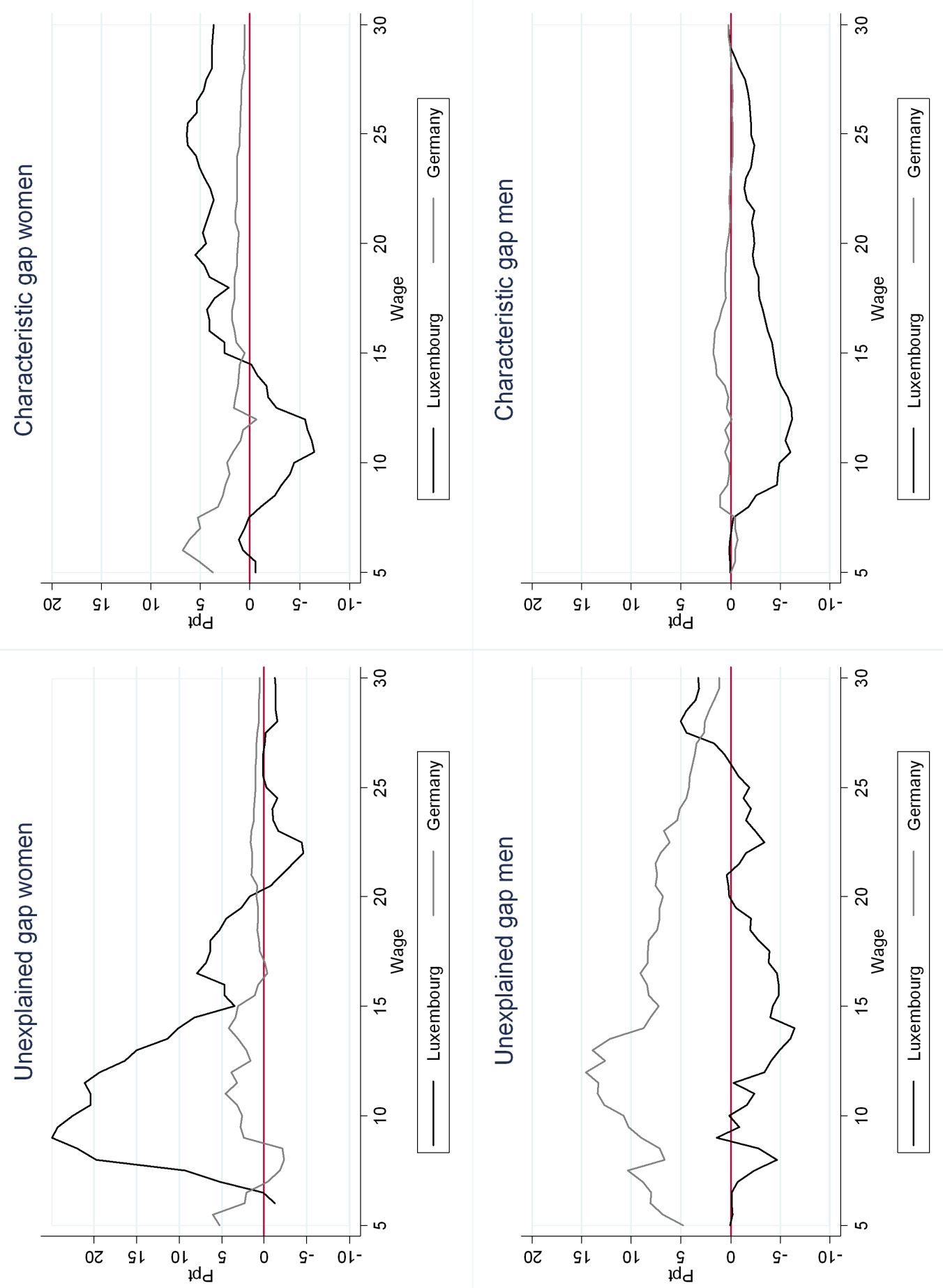

Note: A positive (negative) unexplained gap indicates a beauty premium (penalty) while a positive (negative) characteristic gap indicates that beautiful people have better (worse) labour market characteristics than plain people.

Source: 2008 GSS, 2007 PSELL3 
$\overline{\text { Figure } 4 \text { Unexplained and characteristics gaps between unconfident and confident women }}$ and men across the wage distribution.
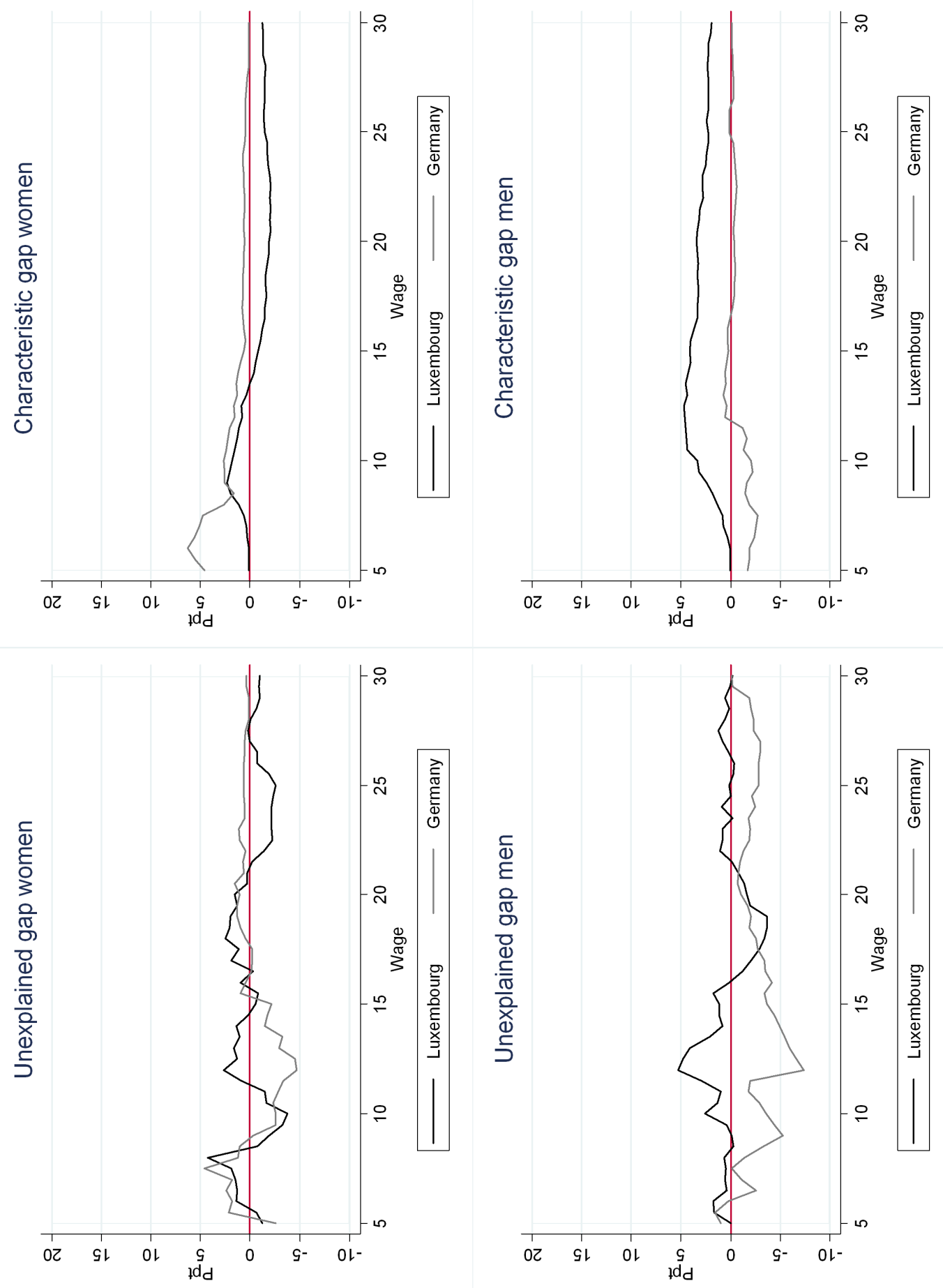

Note: A positive (negative) unexplained gap indicates a confidence premium (penalty) while a positive (negative) characteristic gap indicates that confident people have better (worse) labour market characteristics than unconfident people.

Source: 2008 GSS; 2007 PSELL3 
Figure 5 Unexplained and characteristics gaps with 95\% confidence intervals between plain and beautiful women and men across the wage distribution in Germany.
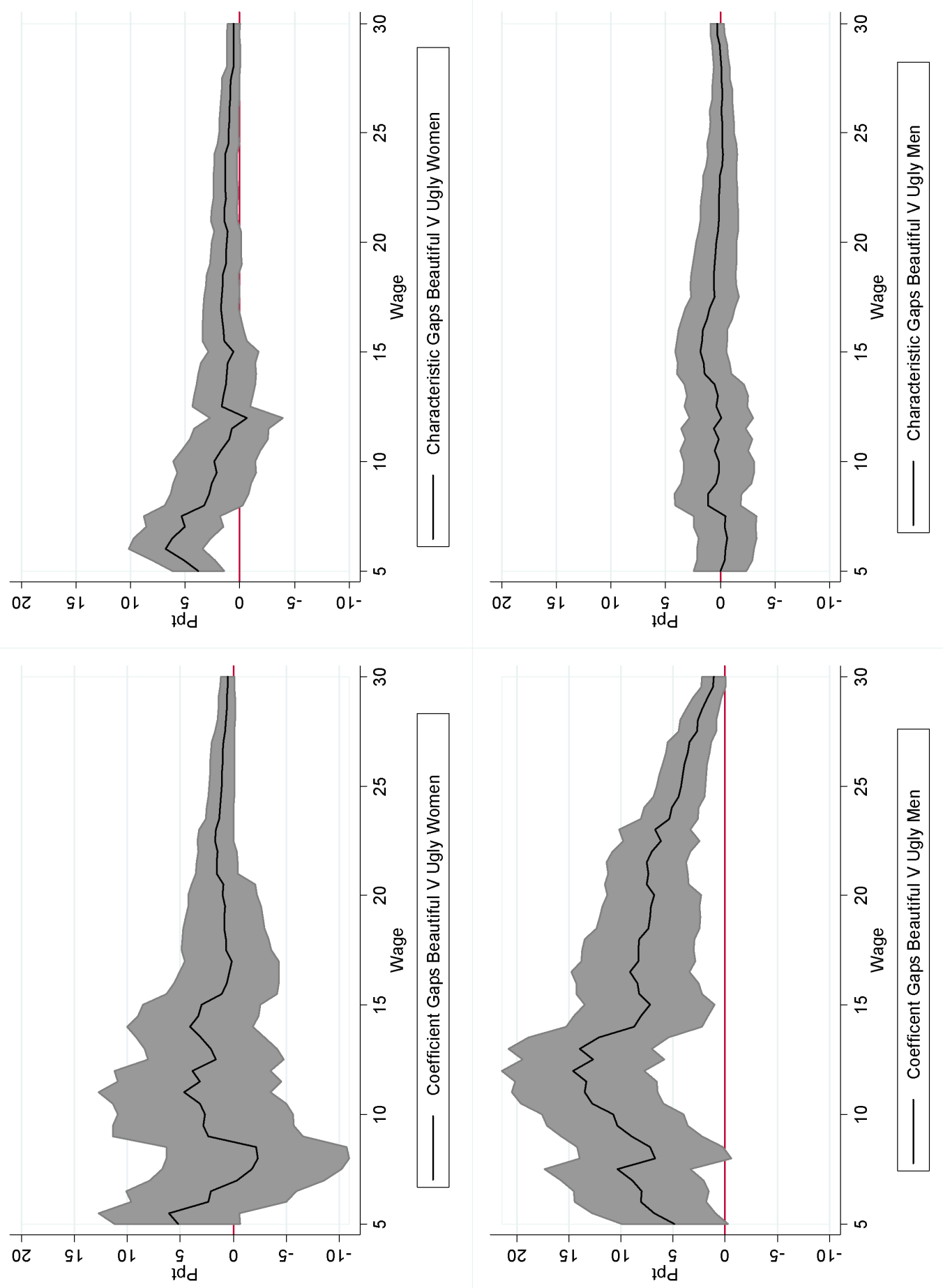

Note: A positive (negative) unexplained gap indicates a beauty premium (penalty) while a positive (negative) characteristic gap indicates that beautiful people have better (worse) labour market characteristics than plain people.

Source: 2008 GSS 
Figure 6 Unexplained and characteristics gaps with 95\% confidence intervals between plain and beautiful women and men in the dressy profession across the wage distribution in Germany.
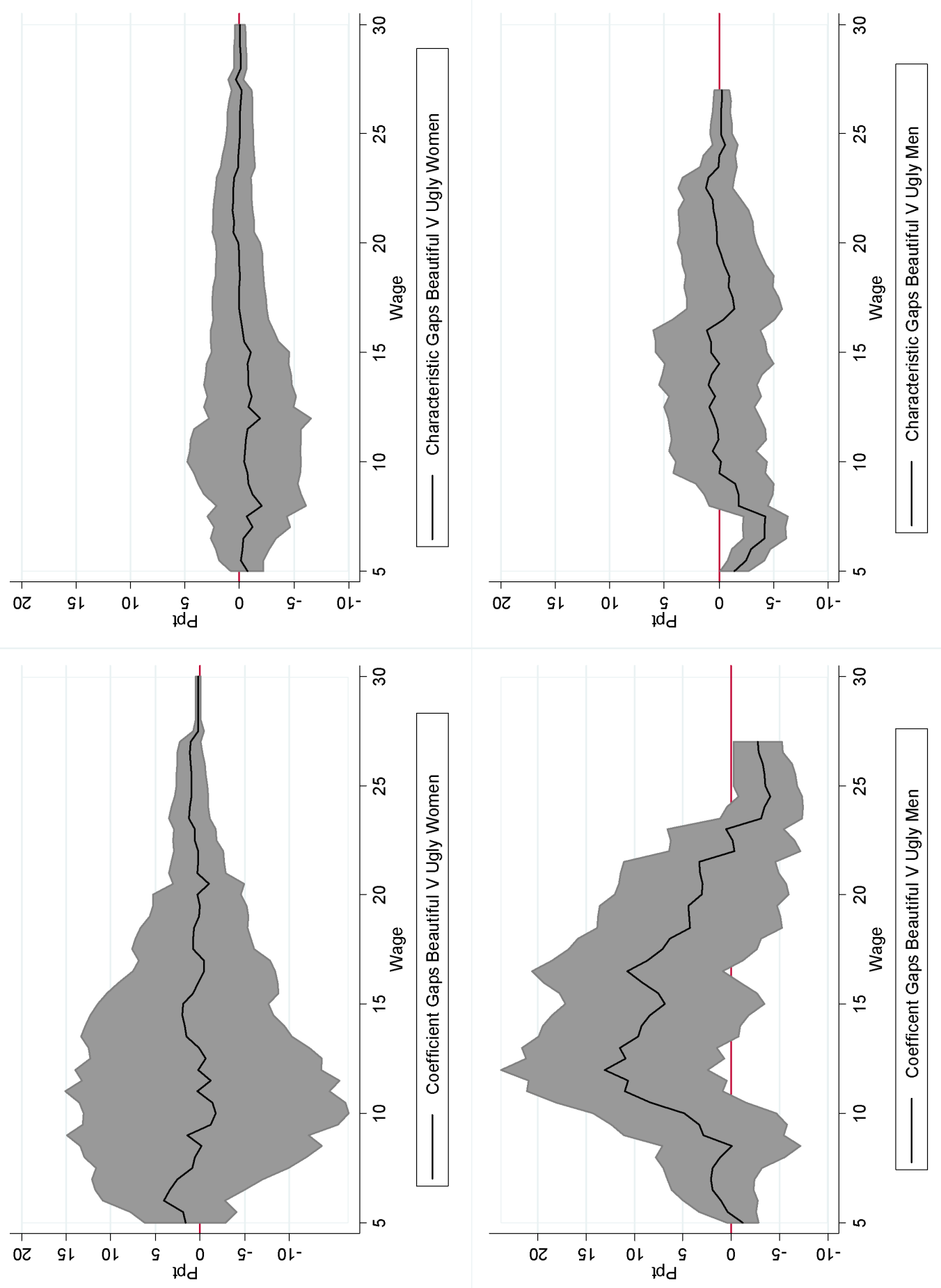

Note: A positive (negative) unexplained gap indicates a beauty premium (penalty) while a positive (negative) characteristic gap indicates that beautiful people have better (worse) labour market characteristics than plain people. 
Figure 7 Unexplained and characteristics gaps with 95\% confidence intervals between plain and beautiful women and men under 45 across the wage distribution in Germany.
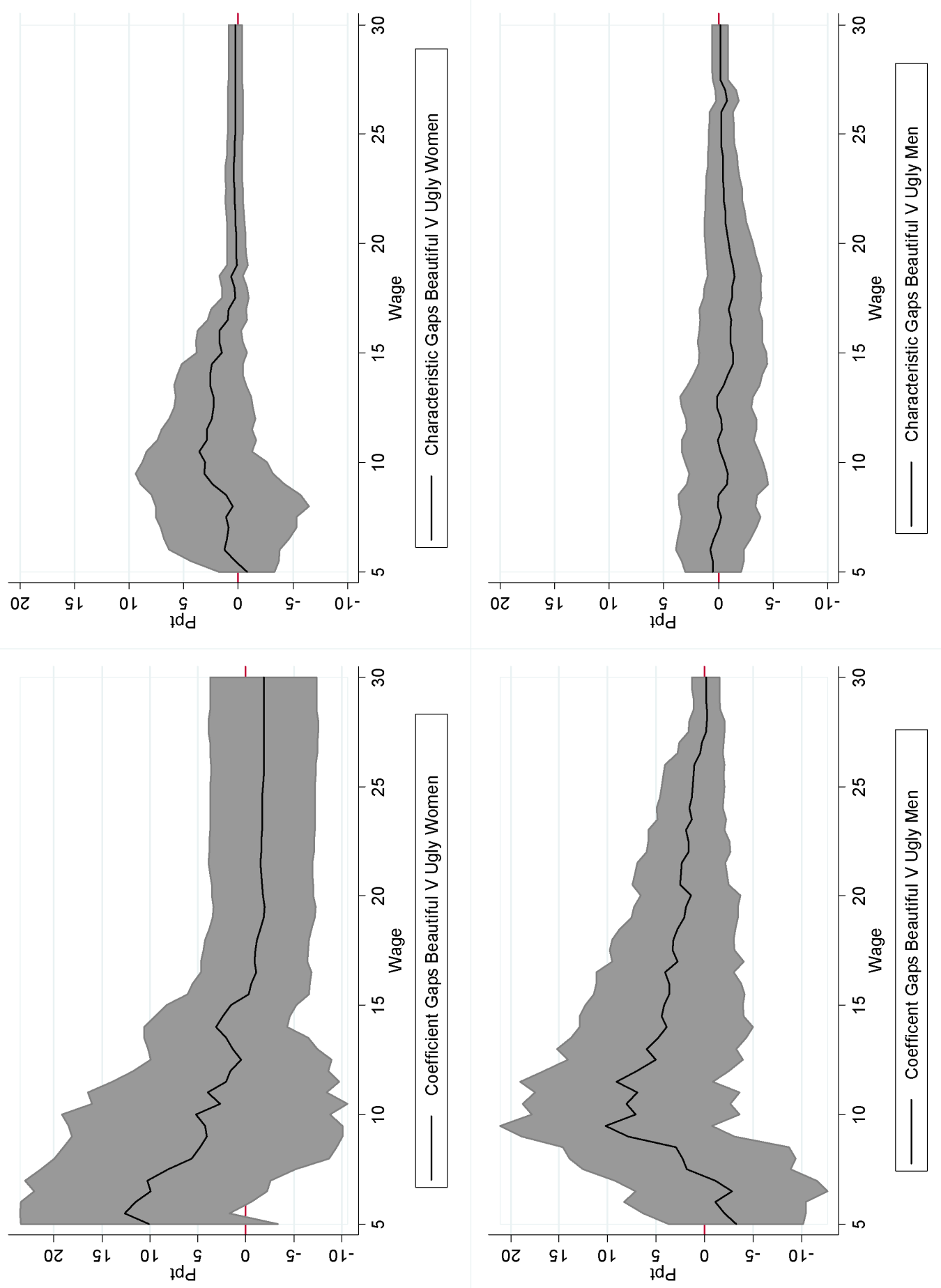

Note: A positive (negative) unexplained gap indicates a beauty premium (penalty) while a positive (negative) characteristic gap indicates that beautiful people have better (worse) labour market characteristics than plain people.

Source: 2008 GSS 
Figure A1 Self-assessed beauty by occupation (in percentages).
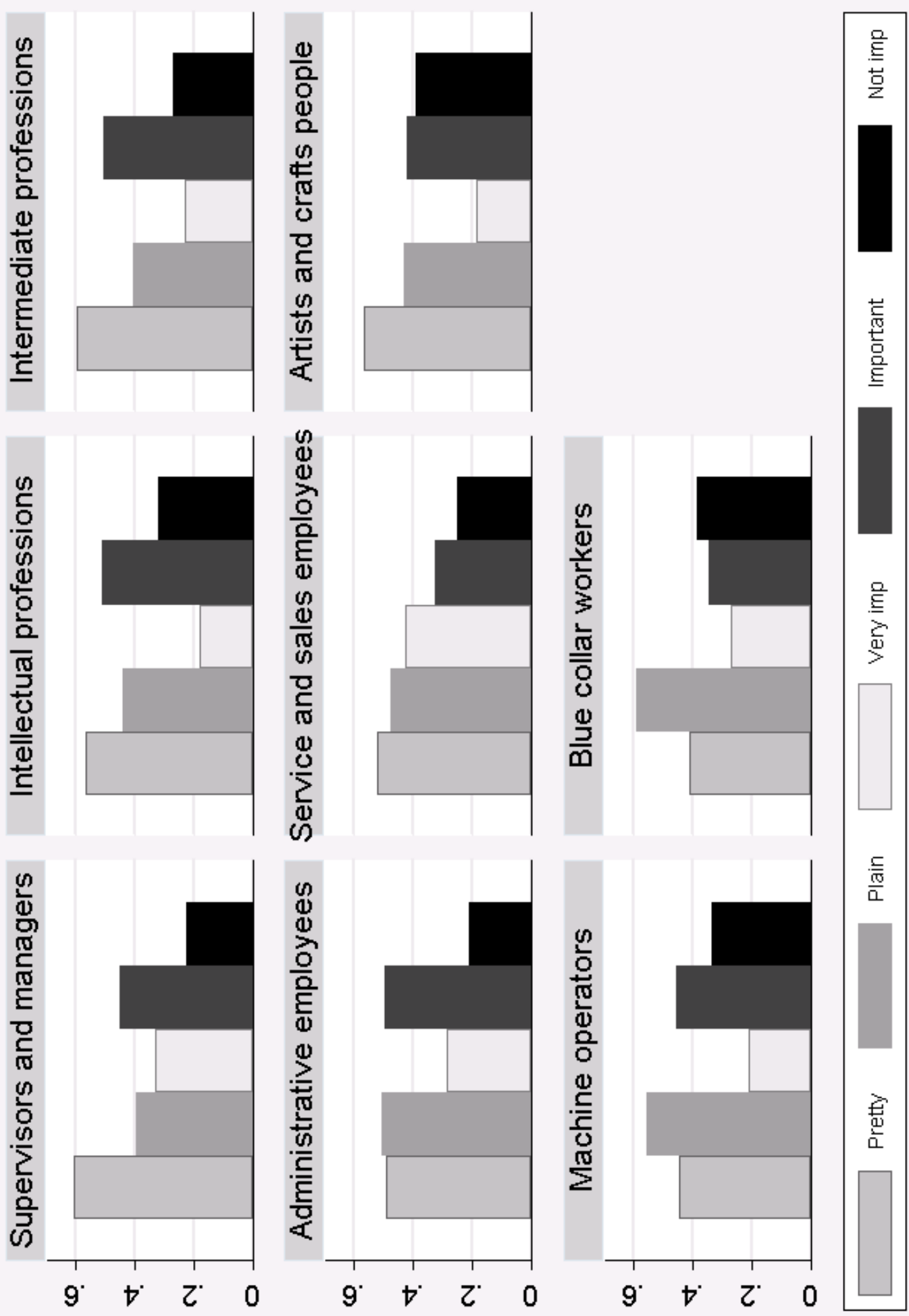

Source: 2007 PSELL3 
Table A1: Select statistics for women and men in Luxembourg.

\begin{tabular}{lccl}
\hline \hline & & & \\
& Women & Men & diff \\
\hline Age & 37.325 & 38.104 & $-0.779^{* *}$ \\
married & 0.551 & 0.611 & $-0.060^{* * *}$ \\
single & 0.311 & 0.307 & 0.004 \\
separated & 0.138 & 0.082 & $0.056^{* * *}$ \\
no. children & 1.226 & 1.283 & -0.057 \\
children (0/1) & 0.653 & 0.643 & 0.010 \\
lt high school & 0.335 & 0.356 & -0.020 \\
high school & 0.305 & 0.328 & -0.023 \\
college & 0.348 & 0.310 & $0.038^{* *}$ \\
Work experience & 15.304 & 18.522 & $-3.218^{* * *}$ \\
full-time & 0.686 & 0.979 & $-0.293^{* * *}$ \\
part-time & 0.369 & 0.036 & $0.334^{* * *}$ \\
big company & 0.454 & 0.556 & $-0.103^{* * *}$ \\
temporary contract & 0.107 & 0.099 & 0.008 \\
civil servant & 0.222 & 0.181 & $0.042^{* * *}$ \\
Native & 0.387 & 0.367 & 0.020 \\
Portugese & 0.239 & 0.282 & $-0.043^{* * *}$ \\
Other non-native & 0.374 & 0.351 & 0.023 \\
bad health & 0.035 & 0.025 & $0.010^{*}$ \\
great health & 0.378 & 0.393 & -0.015 \\
Occupation Type: Dressy & 0.749 & 0.579 & $0.170^{* * *}$ \\
\hline \hline 2007 PSELL-3; t statistics in parentheses * $0<0.1 * * \mathrm{p}<0.05 * * * \mathrm{p}<0.01$
\end{tabular}


Table A2: Select statistics for women and men in Germany.

\begin{tabular}{lccl}
\hline \hline & & & \\
& Women & Men & diff \\
\hline age & 43.185 & 43.678 & -0.493 \\
married & 0.591 & 0.577 & 0.014 \\
single & 0.240 & 0.322 & $-0.082^{* * *}$ \\
separated & 0.167 & 0.101 & $0.066^{* * *}$ \\
no. children & 0.675 & 0.533 & $0.141^{* * *}$ \\
children (0/1) & 0.389 & 0.306 & $0.084^{* * *}$ \\
low education & 0.243 & 0.240 & 0.002 \\
medium education & 0.386 & 0.381 & 0.005 \\
high education & 0.371 & 0.378 & -0.007 \\
full-time & 0.308 & 0.669 & $-0.360^{* * *}$ \\
part-time & 0.584 & 0.290 & $0.294^{* * *}$ \\
big company & 0.204 & 0.310 & $-0.106^{* * *}$ \\
civil servant & 0.158 & 0.132 & $0.026^{*}$ \\
bad health & 0.125 & 0.117 & 0.008 \\
great health & 0.646 & 0.670 & -0.024 \\
old fashioned & 0.516 & 0.628 & $-0.111^{* * *}$ \\
working spouse & 0.461 & 0.365 & $0.096^{* * *}$ \\
occupation type: dressy & 0.761 & 0.453 & $0.308^{* * *}$ \\
\hline \hline
\end{tabular}

Source: 2008 GSS; $\mathrm{t}$ statistics in parentheses $* \mathrm{p}<0.1 * * \mathrm{p}<0.05 * * * \mathrm{p}<0.01$ 